\title{
O PROCESSO JUDICIAL ELETRÔNICO COMO INSTRUMENTO DE CONCRETIZAÇÃO DO DIREITO FUNDAMENTAL À CELERIDADE DA PRESTAÇÃO DA TUTELA JURISDICIONAL
}

ADRINA JOSÉLEN ROCHA MORAIS BARBOSA 


\title{
O PROCESSO JUDICIAL ELETRÔNICO COMO INSTRUMENTO DE CONCRETIZAÇÃO DO DIREITO FUNDAMENTAL À CELERIDADE DA PRESTAÇÃO DA TUTELA JURISDICIONAL
}

Recebimento: $24 / 04 / 2013$

Aceite: $30 / 10 / 2013$

Adrina Josélen Rocha Morais Barbosa ${ }^{1}$

\section{RESUMO}

Com a exigência do provimento judicial em tempo razoável após a Emenda Constitucional n ${ }^{\circ} 45$, de 2004, e a Lei $\mathrm{n}^{\circ} 11.419$, de 2006, possibilitando o emprego da internet como meio de transmissão de dados processuais, o Poder Judiciário foi definitivamente inserido na era do desenvolvimento tecnológico, haja vista a implantação do processo eletrônico que conferiu ao trâmite processual o ritmo compatível com a prestação da tutela jurisdicional justa.

Palavras-Chave: Processo Eletrônico. Princípios Constitucionais. Celeridade.

\begin{abstract}
After the Constitutional Amendment number 45/04 and Law number $11.419 / 06$, the requirement of judicial provision within a reasonable time, that allowed internet usage as a means of data transmission procedure, the Judiciary has definitely entered the era of technological development, due to the implementation of e-Proc, which gave the procedural action, a compatible pace with the courts fair.

1 Bacharel em Direito pela Universidade de Mogi das Cruzes-SP. Especialista em Direito Civil e Direito Processual Civil pela Universidade do Tocantins. Pós-Graduanda em Criminologia pela Escola Superior da Magistratura Tocantinense. Assessora Jurídica de Desembargador no TJTO.
\end{abstract}


KEYWORDS: The eprocess. Constitutional Principles. Celerity.

\section{INTRODUÇÃO}

A Emenda Constitucional $n^{\circ} 45$, de 2006, acrescentou ao texto magno o princípio da razoabilidade da duração do tempo do trâmite processual e, assim, inaugurou uma era institucional de combate à morosidade judicial, pois configurada como contramão do desenvolvimento social.

Com o advento da Lei $\mathrm{n}^{\mathrm{o}} 11.419$, de 2006, possibilitando o emprego da internet como meio de transmissão de dados processuais, o Poder Judiciário, abarrotado de demandas patologicamente lentas, foi definitivamente inserido na era do desenvolvimento tecnológico e atualmente caminha a passos largos rumo à plenitude do cumprimento à efetividade da tutela jurisdicional eficaz.

Após a implantação do processo eletrônico, o trâmite processual assumiu o ritmo do desenvolvimento tecnológico e social da população mundial. A prestação da tutela jurisdicional está deixando no passado o estigma da insatisfação do jurisdicionado que, a cada dia, renova sua confiança no provimento judicial justo.

$\mathrm{O}$ e-Proc, que rompeu as barreiras da incredulidade e do pessimismo, representa a reestruturação da tutela jurisdicional que, subsidiada pelos recursos da tecnologia da informação, atualmente evidencia a capacidade de o Poder Judiciário cumprir a finalidade de fazer justiça. 


\section{A EMENDA CONSTITUCIONAL No 45, DE 2004, E A POSITIVAÇÃO DO PRINCÍPIO DA RAZOABILIDADE}

A Convenção Americana de Direitos Humanos de 1969, ratificada pelo Brasil em 1992, ao estabelecer que "toda pessoa tem direito a ser ouvida com as garantias e dentro de um prazo razoável por um juiz ou tribunal competente", incorporou ao ordenamento pátrio, o direito à razoabilidade no prazo de tramitação processual, égide contemplada, a priori, no artigo $6^{0}$ da Convenção Europeia de Direitos Humanos de 1950, e, posteriormente, na Constituição da República Portuguesa de 1976, demonstrando que a preocupação com a morosidade da justiça, além de não ser contemporânea, é mundial.

A Emenda Constitucional no 45, de 2004, ao contemplar os ditames do Pacto de San José da Costa Rica de 22 de novembro de 1969, promulgado no Brasil pelo Decreto $n^{\circ} 678$, de 1992, a exemplo do texto constitucional português o qual dispõe em seu artigo 20 que "todos têm direito a que uma causa em que intervenham seja objecto de decisão em prazo razoável e mediante processo equitativo", inseriu o inciso LXXVIII ao artigo $5^{\circ}$ da Carta Magna estabelecendo que "a todos, no âmbito judicial e administrativo, são assegurados a razoável duração do processo e os meios que garantam a celeridade de sua tramitação" para uma efetiva tutela jurisdicional.

A Emenda $n^{\circ} 45$, de 8 de dezembro de 2004, representa a positivação do direito à dignidade humana, princípio amplamente difundido no bojo dos textos legais assecuratórios do direito 
ao devido processo legal e à efetividade da justiça. Elevado à condição de cláusula pétrea, o direito à razoabilidade no prazo de tramitação dos feitos judiciais evidencia o compromisso constitucional com a valorização do ser humano por meio da utilidade das decisões judiciais.

Ao atribuir pleno status de garantia constitucional ao princípio da brevidade, movido pelos percalços sociais da demora patológica do processo, o legislador constituinte buscou imprimir maior efetividade ao trâmite processual, tornando-o mais justo e consentâneo com as necessidades dos cidadãos, visto que, à época da arcaica sistemática processual física, era uníssona a insatisfação social acerca da morosidade do Poder Judiciário, desafiando providências estatais para uma contraprestação judicial célere; com esse mister, o liame definitivo entre a prestação jurisdicional e internet tornouse questão de tempo, "uma tendência evidente, em razão das inovações da tecnologia e dos anseios da sociedade moderna" (MARINONI, 2011, p. 115).

A reforma constitucional alavancou o uso da tecnologia no processo judicial e legitimou a concepção contemporânea do desenvolvimento do direito processual com a modernização da ciência jurídica em prol do cidadão. Deve-se ter em mente que, à medida que "um Estado passa a reconhecer e proteger Direitos Fundamentais, tais direitos passam a demarcar o perfil desse Estado, prenunciando a sua forma de agir e de como ele se relaciona com os indivíduos que, na sua dimensão subjetiva, o integram" (ARAÚJO; NUNES JÚNIOR, 2012, p. 131-132). 
Embora a razoabilidade do prazo para a prestação da tutela jurisdicional tenha sido contemplada em Pactos e Convenções anteriores, somente após sua previsão "na Constituição Federal pela Emenda Constitucional $n^{\circ} 45$, de 2004, foi despertada a devida atenção pela legislação infraconstitucional [...] como ideal da justiça brasileira para o processo judicial" (PEREIRA, 2011, p. 51).

Não obstante a controvérsia acerca do constitucionalismo nacional e da hierarquia do ordenamento jurídico pátrio, a recepção de tratados e convenções internacionais como Emenda à Constituição, pelo texto magno após a Emenda Constitucional $\mathrm{n}^{\mathrm{o}} 45$, consubstancia dinâmica inovadora de ratificação da relevância dos direitos fundamentais, ao passo que reconhece o caráter universal dos direitos humanos.

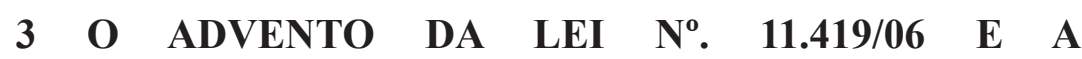 INFORMATIZAÇÃO DA TUTELA JURISDICIONAL}

Impulsionada pela celeridade impressa no artigo $5^{\circ}$, LXXVIII, da Constituição Federal como direito fundamental, a Lei no 11.419, de 2006, regulamentou a inserção da justiça na conjuntura da tecnologia da informação, aprioristicamente positivada com a Lei $n^{\circ}$ 9.800, de 1999, ou Lei do Fax, que permitia às partes a utilização de sistema de transmissão de dados e imagens tipo fac-símile ou outro similar, para a prática de atos processuais que dependiam de petição escrita, e, posteriormente, com a Lei $n^{\circ} 10.259$, de 2001, que criou o 
Juizado Especial Federal e autorizou, em seu artigo $8^{\circ}, \S 2^{\circ}$, intimações e peticionamentos por meio eletrônico.

A Lei $\mathrm{n}^{\circ} 11.280$, de 2006, ao ratificar a dialética do texto constitucional, alterou o artigo 154 do Código de Processo Civil e expressamente incorporou ao Codex a prática de atos processuais por meio eletrônico, a fim de viabilizar o trâmite processual nos termos da "instantaneidade e facilidade da transmissão de informações por meio da interconectividade proporcionada pela Internet, minimizando assim as barreiras do tempo e do espaço" (DANTAS NETO, 2011, p. 174). Complementa Pereira:

Como visto, a tecnologia vem aos poucos, sendo utilizada na prática processual mudando a realidade da rotina cartorária e dos procedimentos com vistas a celeridade processual e a efetividade da justiça, mas somente com a Lei 11.419/2006, se instituiu para todas as instâncias, tribunais e ritos o processo judicial digital, com tramitação via internet (PEREIRA, 2011, p. 37-38).

A Lei $\mathrm{n}^{\circ} 11.419$, de 2006, acima referida, promovendo a inclusão do $\S 2^{\circ}$ ao artigo 154 do Código de Processo Civil, assevera que "todos os atos e termos do processo podem ser produzidos, transmitidos, armazenados e assinados por meio eletrônico, na forma da lei", de modo a tutelar o processamento de petições on-line no ordenamento jurídico brasileiro com a implantação do sistema eletrônico de tramitação processual, e atender ao anseio de concretização da cidadania. Moraes (2011, p. 116) define meio eletrônico "como qualquer forma de 
armazenamento ou tráfego de documentos e arquivos digitais".

Nesse contexto, a Lei $\mathrm{n}^{0} 11.419$, de 2006, no que concerne à instantaneidade da aplicação do direito no combate ao cenário jurisdicional defasado que engessava a sistemática processual, representa a modernização e o aperfeiçoamento do Poder Judiciário na busca pelo cumprimento da função social do processo, posto que "o processo judicial virtual reduz o tempo de tramitação, abrevia a concretização do comando das decisões judiciais restituindo mais rápido a paz social e a justiça" (CLEMENTINO, 2009, p 158).

O intuito do legislador com a edição da Lei $n^{0} 11.419$, de 2006, era a mudança estrutural do Poder Judiciário, com vistas à concretização do direito constitucional à razoável duração do processo e à justiça célere, pois, com os avanços propiciados pela globalização, o conceito de celeridade judicial é indissociável da aplicação das novas tecnologias de transmissão virtual de dados. Acerca do tema, Freire e Bernardes estabelecem que:

O termo virtual traduz de forma mais ampla o processo atual da sociedade em rede, que está mediada pelo ciberespaço, não se circunscreve a máquina (eletrônica), a linguagem (bits), mas, além disso, está conectada, está na rede, está no ciberespaço, sendo estas as características mais transformadoras e potencializadoras de novas relações, colaborações, interações e de uma mudança substancial nas identidades e senso de lugares (FREIRE, BERNARDES, 2011, p. 3-4).

O texto da lei evidencia o compromisso de o legislador 
assegurar o acesso à justiça ao fomentar, com a criação do Diário da Justiça eletrônico, a busca pelos atos do Poder Judiciário com um simples clique e pela dilação do dies ad quem ao assegurar a tempestividade com o envio da petição eletrônica até às 24 horas.

\section{SISTEMA E-PROC E A CONCRETIZAÇÃO DA CELERIDADE PROCESSUAL}

De salutar conveniência para a modernização na seara judicial, o sistema processual eletrônico desponta como meio operacional da concretização do princípio da brevidade do processo, cujo status de direito fundamental, conferido pela Constituição Federal, evidencia o empenho de o legislador adequar a prestação jurisdicional com a evolução das necessidades sociais, pois "o resultado esperado da técnica processual há de se operar no campo das relações substanciais. É na produção desses resultados, em nível satisfatório, que se poderá definir a maior ou menor efetividade do processo" (THEODORO JÚNIOR, 2010, p. 16).

O intento da Lei do Processo Eletrônico em erradicar o estigma da morosidade processual é evidenciado pelo fato de que, cadastrada no processo digital pela parte, a exordial é automaticamente protocolizada e disponibilizada à análise do Julgador, potencializando a concretização do direito com a eliminação dos entraves da burocracia judicial.

A informatização do processo judicial, seguindo a 
dinâmica das novas tecnologias, é um instrumento profícuo à modernidade da justiça, e prestigia a premissa do acesso de todos a uma ordem jurídica justa e consentânea com as pretensões humanas da atualidade. Sobre a tutela jurisdicional, elucida Theodoro Júnior:

Todo titular de direito subjetivo lesado ou ameaçado tem acesso à Justiça para obter,do Estado, a tutela adequada (CF, art. $\left.5^{\circ}, \mathrm{XXXV}\right)$, a ser exercida pelo Poder Judiciário. Nisso consiste a denominada tutela jurisdicional, por meio da qual o Estado assegura a manutenção do império da ordem jurídica e da paz social nela fundada (THEODORO JÚNIOR, 2010, p. 66).

É indubitável ter havido, com a virtualização do processo, acréscimo no número de demandas propostas e, reflexamente, maior volume de trabalho para os operadores do Direito, haja vista a celeridade, no julgamento das ações, estimular o cidadão a demandar por seus direitos, e a comodidade do meio judicial eletrônico viabilizar a atuação do causídico. Entretanto, mencionada majoração, além de ser compensada pelo dinamismo do trâmite processual, demonstra a progressividade com que tem sido reconhecido o atendimento ao princípio do acesso à justiça, e evidencia que o brasileiro está exercendo plenamente o direito fundamental previsto no artigo $5^{\circ}, \mathrm{XXXV}$, da Constituição Federal. Nesse sentido: 
os novos direitos individuais e sociais, uma vez que a titularidade de direitos é destituída de sentido, na ausência de mecanismos para sua efetiva reivindicação. $\mathrm{O}$ acesso à justiça pode, portanto, ser encarado como o requisito fundamental - o mais básico dos direitos humanos - de um sistema jurídico moderno e igualitário que pretenda garantir, e não apenas proclamar os direitos de todos. (CAPPELLETTI, GARTH, 2002, p. 11-12).

A comunicação eletrônica dos atos do processo em todos os âmbitos do Poder Judiciário resulta de uma reforma idealizada para atender ao propósito de simplificação do trâmite processual, vislumbrando reduzir o tempo de espera do cidadão pela entrega da tutela jurisdicional com a valorização da razoabilidade do tempo empregado para dirimir as questões jurídicas trazidas à baila. E o fator tempo "é determinante no estabelecimento de direitos e deveres no ciberespaço, quer pela rapidez exigida para evitar que o direito não se esvazie no caso concreto, quer pela própria manutenção e credibilidade no ordenamento jurídico [...]" (REIS, 2012, p. 105).

O e-Proc, corroborando o mister de uma ordem jurídica equânime e breve o bastante para atender às aspirações da parte, exige de seus usuários uma atividade procedimental escorreita, escorada na ideologia de salvaguardar a tendência hodierna de patrocinar alterações relevantes na sistemática processual e abreviar o prazo da análise judiciária, mormente pelo fato de que, "justiça tardia é justiça desmoralizada" (LOPES DA COSTA apud THEODORO JÚNIOR, 2010, p. 33).

$\mathrm{O}$ e-Proc, configurado como instrumento de tramitação 
da demanda, depende da manifestação humana, não é autônomo, desenvolve-se por meio de ações comissivas de alimentação do sistema com os elementos necessários ao desenvolvimento do feito, consubstanciados, dentre outras hipóteses, em exarar ciente, protocolizar e juntar documentos.

A Instrução Normativa $n^{\circ}$ 05, de 2011, que regulamenta o Processo Judicial Eletrônico - e-Proc no âmbito do Poder Judiciário do Estado do Tocantins, estabelece em seu artigo 12 que "os documentos indispensáveis à propositura da ação, bem como todas as petições destinadas aos autos do e-Proc, deverão ser juntados na forma eletrônica e adequadamente classificados", revelando que a virtualização do processo judicial, divorciada do comprometimento dos profissionais do Direito, não é suficiente como instrumento de implementação da jurisdição célere, e a atuação do usuário do sistema judicial eletrônico é decisiva à concretização da justiça diligente.

Na seara da justiça virtual, qualquer elemento probatório ou instrutório que componha uma demanda é denominado como documento eletrônico, que na concepção de Maria Neuma Pereira (2011, p. 92) é:

[...] todo documento produzido eletronicamente que atenda aos requisitos de validade ou ainda que não produzidos eletronicamente tenha sido digitalizado e inserido num sistema eletrônico com a chancela da assinatura digital, pois conforme o artigo 11, parágrafo, $1^{\circ}$, da Lei 11.419/2006 [...].

Insensato imaginar que na era do processo judicial eletrônico, a parte tenha de ser intimada para retificar a 
juntada de documentos, componentes essenciais ao suporte da instrução e desenvolvimento válido do processo, os quais devem preencher requisitos de funcionalidade que desafiam a juntada de anexos devidamente relacionados, inteligíveis, cronológicos e adequadamente agrupados.

Ressalte-se que limitar o tamanho dos documentos eletrônicos enviados não éa solução viável, pois, em determinados casos, haverá documento imprescindível ao processamento do feito, o qual, por si só, ocupará todo o espaço permitido, tratando-se, in casu, de questão de bom senso e compromisso de cooperação com o Poder Judiciário na tarefa de concretizar a tutela jurisdicional justa.

Uma atuação descomprometida dos usuários do sistema pode obstar o pleno desenvolvimento da jurisdição eletrônica, pois a virtualização do processo desafia a funcionalidade dos documentos anexados ao sistema judicial eletrônico, com vistas a assegurar o regular trâmite dos autos, reprimindo-se o proceder tendente à inobservância das garantias constitucionais.

Os preceitos éticos impõem aos operadores do Direito um proceder consentâneo com a brevidade na realização da justiça, mormente pelo fato de que a era judicial eletrônica não comporta posturas contraproducentes com o ânimo constitucional de agilidade, não havendo possibilidade de êxito no atendimento às partes com celeridade isonômica quando estas se conduzem de modo a dificultar a prestação jurisdicional. Segundo Carnelutti apud Humberto Theodoro Júnior (2010, p. 81), “o processo, como instituição jurídica, é uma sequência de atos das partes e 
do órgão judicial tendentes à formação ou atuação do comando jurídico".

A exigência de igualdade deve ser compreendida [...] num sentido relativo, isto é, como uma exigência de que os iguais sejam tratados da mesma maneira. Isto significa que, como um pré-requisito para a aplicação da norma de igualdade e com independência dela, é preciso que haja algum critério para determinar o que será considerado igual; em outras palavras, a exigência de igualdade contida na ideia de justiça não é dirigida de forma a todos e a cada um, mas a todos os membros de uma classe determinados por certos critérios relevantes (ROSS, 2000, p. 315).

O processo eletrônico possibilita a prática de atos processuais a qualquer momento e a partir de qualquer meio de acesso à rede mundial de computadores, facilitando a atuação dos juristas, principalmente advogados públicos e privados que, com a era digital, passaram a ter maior autonomia e independência no que concerne ao tempo e ao ambiente de trabalho, visto que suprimida a obrigatoriedade da presença física nas dependências do Poder Judiciário para o protocolo, movimentação e consulta dos autos, abreviando o tempo empregado em cada caso concreto, cumprindo-lhes, em contrapartida, atuar de forma a cooperar com a eficiência da justiça.

Mudanças demandam tempo, entretanto, para que o Poder Judiciário possa promover a verdadeira efetividade da justiça, é premente que todos os operadores do Direito estejam dispostos à modernização, e se adaptem à nova conjuntura jurídico- 
tecnológica para efetividade da justiça, haja vista a implantação do processo judicial eletrônico, por si só, ser insuficiente, desafiando o engajamento de todos os juristas para o fim comum de fazer justiça. Com efeito:

O processo judicial nada mais é do que um instrumento de acesso à justiça, sendo certo que ao jurisdicionado não basta que se lhe assegure a prerrogativa de demandar, de pleitear a tutela que venha a satisfazer o interesse jurídico que o mova ao exercício do direito de ação. Imperioso é que o processo traga resultados práticos ao demandante, obtendo este os efeitos que almeja para o que, sem o processo, permanecer-lhe-iam inalcançáveis (GALAN, 2011, p. 214-215).

Nesse contexto, infere-se que não basta à parte chegar até o Poder Judiciário, é necessário lograr êxito na pretensão jurisdicional e "com a implantação plena da informatização do processo nos órgãos jurisdicionais, é impossível pensá-la incapaz de promover a almejada celeridade processual" (DE PAULA, 2010, p.114), sendo que a prestação morosa da justiça equivale à injustiça, e pode significar o perecimento do direito pretendido, corroborando a máxima de que "Justiça que tarda é Justiça falha, pois gera impunidade e descrença no sistema jurídico" (MORAES, 2011, p. 537). Nesse diapasão, Silva destaca:

Um processo extremamente seguro, mas excessivamente lento é tão inadequado quanto outro bastante rápido, mas sem nenhuma segurança, tendo que se buscar formas de equilibrar a balança, garantindo um processo rápido quanto possível, para obter uma maior segurança nos 
provimentos jurisdicionais (SILVA, 2008, p. 166/167).

Para Galan (2011, p. 215), “os reflexos práticos da função jurisdicional exercida pelo Estado devem se fazer sentir pelo jurisdicionado, sob pena de ineficiência do poderfunção". Nesse sentido, propiciando um trâmite processual desembaraçado, o e-Proc, como instrumento de celeridade do direito à tutela jurisdicional justa e adequada, deixou de ser uma promessa, sagrando-se como grata realidade, e devolveu ao sistema jurídico nacional a credibilidade que sucumbira com o estigma da morosidade na solução de conflitos, vencendo a resistência e a incredulidade do cidadão na busca pela garantia dos seus direitos.

O e-Proc representa a valorização do direito fundamental à tutela jurisdicional efetiva e resguarda a dignidade humana do cidadão por meio de uma justiça substancial que consigna a exatidão do direito postulado pela parte, em prazo razoável o suficiente à utilidade do provimento judicial, visto que, segundo Chiovenda apud Humberto Theodoro Júnior (2010, p. 16), “o processo tem de dar ao litigante, tanto quanto possível, tudo o que tem direito de obter segundo as regras substanciais".

Nesse diapasão, leciona Almeida Filho (2011, p. 95) que “o processo, em sua visão instrumentalista, necessita de meios para atingir ao seu fim, que é a pacificação da sociedade". Portanto, o e-Proc, ferramenta judicial tecnológica da era globalizada, é o meio adequado para a quebra de paradigmas arcaicos acerca do desenvolvimento da atividade jurisdicional, um progresso 
definitivo rumo à positivação dos direitos constitucionais dos jurisdicionados.

\section{CONSIDERAÇÕES FINAIS}

O processo virtual é uma realidade irreversível, resultado do avanço tecnológico propiciado aprioristicamente, pela Emenda Constitucional $\mathrm{n}^{\mathrm{o}} 45$, de 2004, a qual, com o inciso LXXXVIII do artigo $5^{\circ}$ da Carta Magna, ressalta que ao ser humano deve ser assegurada a utilidade do pronunciamento judicial, pois justiça tardia é injustiça.

É inquestionável o avanço social que a Lei no ${ }^{\circ} .11 .419$, de 2006, representa, haja vista o dinamismo do trâmite processual imprimido pela virtualização dos autos e, consequentemente, os frutos colhidos pelo jurisdicionado que obtém uma resposta judicial eficiente ao atendimento de seus interesses, uma vez que o processo judicial eletrônico é um instrumento de concretização do direito fundamental à celeridade da prestação da tutela jurisdicional.

Há de se ter em mente que o e-Proc não é propriedade do Poder Judiciário, mas um instrumento social de realização do Direito. Nesse mister, exige que seus operadores procedam com ética e lealdade processual e evitem os expedientes postergatórios que atravancam a entrega da tutela jurisdicional, sob pena de tornar inócua a exigência de razoabilidade impressa no artigo $5^{\circ}$, LXXVIII, da Constituição Federal.

Com o tempo, a legislação avançará no sentido de 
regulamentar as questões técnicas e procedimentais que surgirão com a nova realidade judicial eletrônica. Entretanto, nesse ínterim, os usuários do sistema devem se pautar por métodos e técnicas de atuação que visem à melhoria e ao aprimoramento do cotidiano processual informatizado, principalmente no que concerne à identificação e triagem de peças e documentos. Conclui-se, logicamente, que devem ser juntados somente elementos úteis à demanda, haja vista a análise de atos e fatos dispensáveis ou estranhos à relação jurídica obstar o andamento ágil do feito e, consequentemente, o provimento judicial célere.

Ter critério no comenos da elaboração de petições e juntada de documentos, não implica exclusivamente em facilitação do trabalho do Poder Judiciário, mas em cooperação com a justiça. Além de atender aos preceitos constitucionais concernentes à valorização dos direitos fundamentais dos jurisdicionados, mencionado proceder reverte em favor da parte e, reflexamente, em benefício do respectivo operador do Direito que colherá os frutos do seu ofício em lapso temporal conciso, e cujo nome será sinônimo de credibilidade e eficiência.

O processo eletrônico representa uma transformação cultural, consubstancia uma nova forma de ver e pensar a justiça, um meio de solução da morosidade e da burocracia que imperavam com o processo exclusivamente físico. Não deve ser visto como vaidade institucional do Poder Judiciário, haja vista que este somente se utiliza do sistema para realizar a justiça. Os beneficiários são as partes, sejam elas públicas ou privadas, por isso, cumpre aos destinatários, servidores, membros do Poder 
Judiciário, Ministério Público, advocacias, partes e sociedade em geral, uma atuação interligada, visando ao fim comum: a entrega da tutela justa.

\section{REFERÊNCIAS}

ALMEIDA FILHO, José Carlos de Araújo. Processo eletrônico e teoria geral do processo eletrônico: a informatização judicial no Brasil. 4. ed. Rio de Janeiro: Forense, 2011.

\section{Anexo ao Decreto que Promulga a Convenção Americana} sobre os Direitos Humanos (Pacto de San José da Costa Rica). Disponível em: <http://www.planalto.gov.br/ccivil_03/ decreto/1990-1994/anexo/and678-92.pdf>. Acesso em: 12 mar 2013.

ARAÚJO, Luiz Alberto David; NUNES JÚNIOR, Vidal Serrano. Curso de direito constitucional. 16 ed. São Paulo: Editora Verbatim, 2012.

BRASIL. Lei nº 11.419 de 19 de dezembro de 2006. Disponível em: $\quad<$ http://www.planalto.gov.br/ccivil_03/_ato20042006/2006/lei/111419.htm>. Acesso em: 19 abr 2013.

CAPPELlETTI, Mauro; GARTH, Bryant. Acesso à justiça. Trad. Ellen Gracie Northfleet. Porto Alegre: Sérgio Antônio Fabris, 2002. 
CHAVES JÚNIOR, José Eduardo de Resende (Coord.). Comentários à lei do processo eletrônico. São Paulo: LTR, 2010.

CLEMENTINO, Edilberto Barbosa. Processo judicial eletrônico. Curitiba: Juruá, 2009.

Convenção Europeia dos Direitos Humanos. Disponível em: $\quad<$ http://www.oas.org/es/cidh/expresion/showarticle. asp? $\operatorname{artID}=536 \& 1 \mathrm{ID}=4>$. Acesso em: 05 jan 2013.

DANTAS NETO, Renato de Magalhães. Autos virtuais: o novo layout do processo judicial brasileiro. Revista de Processo, São Paulo, v. 36, n. 194, p. 173-203, abr. 2011.

FREIRE, Geovana Cartaxo de Arruda; BERNARDES, Marciele Berger. Políticas públicas para a construção de uma cibercidade. In: V SIMPÓSIO NACIONAL ABCIBER. Florianópolis: UDESC/UFSC, 16 a 18 de novembro de 2011.

GALAN, Débora Regina Honório. O processo civil eletrônico: suas bases principiológicas e legislativas. Revista ESMAT, Palmas, ano 3, n. 3, p. 207-237, jan/dez. 2011.

Instrução Normativa $\mathbf{n}^{\mathbf{0}}$. 05/2011. Disponível em: $<$ http://www. tjto.jus.br/diario/MateriasPublicadas/2011/10/1495/191929. html>. Acesso em: 22 abr 2013. 
MARINONI, Luiz Guilherme; ARENHART, Sérgio Cruz. Processo de conhecimento. 10. ed. São Paulo: Editora Revista dos Tribunais, 2011.

MORAES, Alexandre de. Direito constitucional. 27. ed. São Paulo: Atlas, 2011.

PEREIRA, Maria Neuma. Processo digital: tecnologia aplicada como garantia da celeridade processual. São Paulo: Biblioteca 24 horas, 2011.

PINHEIRO, Patrícia Peck. Direito digital. 4. ed. rev., atual. e ampl. São Paulo: Saraiva, 2010.

PORTUGAL. Constituição da República Portuguesa. Edição Digital - Edições Almedina: Coimbra, 2012. Disponível em: < http://books.google.com.br/ books?id=aEp3U_USGIYC\&printsec $=$ frontcover $\& \mathrm{hl}=\mathrm{pt}-$ $\mathrm{BR} \# \mathrm{v}=$ onepage \&q\&f=false $>$. Acesso em: 17 mar 2013.

REIS, Graziela Tavares de Souza. Sociedade digital e informatização do processo: ponderações sobre novas realidades e novas problemáticas jurídicas. Revista ESMAT, Palmas, ano 4, n. 4, p. 95-125, jan/dez. 2012.

ROSS, Alf. Direito e justiça. São Paulo: EDIPRO, 2000. 
SILVA, Ovídio Baptista. Curso de processo civil. São Paulo: Revista dos Tribunais, 2008. 2 v.

THEODORO JÚNIOR, Humberto. Curso de direito processual civil: teoria geral do direito processual civil e processo de conhecimento. v. I, 51. ed. Rio de Janeiro: Forense, 2010. 